\title{
José Emilio Pacheco: lector y antólogo del modernismo
}

\author{
José Emilio Pacheco: \\ reader and anthologist of Modernism
}

\author{
Rosario Pascual Battista \\ Universidad Nacional de La Pampa-CONICET \\ pascualbattista.rosario@gmail.com
}

Resumen: José Emilio Pacheco (1939-2014) dedicó parte de su producción ensayística a reconstruir el pasado de las letras y, en particular, se interesó por el movimiento modernista. A partir de dos textos antológicos, Antología del modernismo [1884-1921] (1970) y Poesía modernista. Una antología general (1982), y de una selección de notas periodísticas que publicó en la revista mexicana Proceso, Pacheco aspiró a ampliar el espectro de las figuras modernistas y evitar ceñirse a una única figura, como podría ser la del nicaragüense Rubén Darío. Este artículo reconstruye los diálogos y las reciprocidades que José Emilio Pacheco traza con la tradición literaria del modernismo y que se sostienen, por un lado, en las religaciones entre poetas, como es el caso de Manuel Gutiérrez Nájera y José Martí y, por otro lado, en la recuperación de poetas poco reconocidos por la crítica literaria, como Salvador Díaz Mirón.

\author{
Palabras clave: \\ José Emilio Pacheco; \\ antología; \\ ensayo; \\ tradición; \\ modernismo; \\ México.
}

KEYWORDS:

José Emilio Pacheco;

Anthology;

Essay;

Tradition:

Modernism;

Mexico.
ABSTRACT: José Emilio Pacheco (1939-2014) devoted part of his essay production to reconstruct the past of letters and, in particular, was interested in the Modernist movement. From two anthological texts: Anthology of Modernism [1884-1921] (1970) and Modernist Poetry. A General Anthology (1982), and a selection of journalistic notes that he published in the Mexican magazine Proceso, Pacheco aimed at broadening the spectrum of Modernist figures and avoiding to keep to a single figure, such as that of the Nicaraguan Rubén Darío. This article reconstructs the dialogues and reciprocities that José Emilio Pacheco traces with the literary tradition of Modernism and that are sustained, on 
the one hand, in connections between poets, as it is the case of Manuel Gutiérrez Nájera and José Martí and, on the other hand, in the recovering of poets less well-known by literary criticism, such as Salvador Díaz Mirón.

recepción: 25 septiembre 2019

aceptación: 12 febrero 2020

\section{José Emilio Pacheco: antólogo del modernismo}

Tarea ardua y exigente es la preparación de una antología y más si su eje pretende centrarse en uno de los movimientos más controvertidos y discutidos de la literatura latinoamericana: el modernismo. José Emilio Pacheco no teme los riesgos que esta aventura puede presentar y en el año 1970 publica dos tomos dedicados al modernismo de su país bajo el título Antología del modernismo [1884-1921].

Pacheco, como lector de primerísimo rango, sostiene la operación propia de la antología según Alfonso García Morales; esto es, la escisión y reinserción de textos de diferentes autores, quienes "se eligen y se separan de conjuntos textuales previos para ser reunidos, enmarcados y ordenados en un conjunto único, del que reciben y al que confieren sentido, en el que adquieren nuevas relaciones, significaciones y valores" (26). Al advertir la ausencia de una compilación de textos sobre el modernismo mexicano, Pacheco opera sobre un repertorio textual que deja traslucir sus elecciones y preferencias literarias; un corpus que, hasta el momento, aparentemente, no había sido estudiado con la seriedad crítica que él pretende. ${ }^{1}$ Frente al supuesto vacío, Pacheco despliega este proyecto y, así, trata

1 Debemos entender la intervención de José Emilio Pacheco sobre una carencia de un trabajo antológico sobre el modernismo como una estrategia discursiva que le sirve para justificar su propia edición crítica. En México, hacia 1970, ya existe una tradición antológica cuyo inicio en el siglo xx puede ser señalado en 1910, año en que se publica la Antología del Centenario, obra representativa de la cultura porfiriana, patrocinada por el secretario de Instrucción, Justo Sierra, y llevada a cabo por el poeta Luis G. Urbina, el crítico Pedro Henríquez Ureña y el historiador Nicolás Rangel. Incluso, hacia 1892, la Real Academia Española, antes de encomendar a Marcelino 
de saldar la deuda con parte de las letras mexicanas que no poseen lo que él reclama; plantea diferentes lecturas, otros recorridos críticos que apelan a intervenir, como afirma Claudio Guillén (cfr. 1985: 413), en una nueva recepción de poetas, en este caso, los modernistas mexicanos. Debemos aclarar que la enunciación que elige Pacheco para reflexionar y proponer su versión sobre la tradición modernista se enmarca en un campo intelectual que hacia los años setenta ya reconoce su preeminencia en las letras mexicanas. Es un escritor destacado, como bien asevera Isabel Quiñónez (2008: 358), que, además de preparar tres libros de poesía, Irás y no volverás (1969-1972) (1973), Islas a la deriva (1973-1975) (1976) y Desde entonces (1975-1974) (1980), y publicar El principio del placer (1972), el tercer libro de cuentos, en el mismo periodo lleva adelante el trabajo de difusor cultural, y se perfila como uno de los mejores ensayistas de ésta y las próximas décadas con sus "Inventarios" en Proceso, en cuyo primer número (6 de noviembre de 1976) participa. $^{2}$

Menéndez Pelayo una antología sobre la poesía hispanoamericana para celebrar el IV Centenario del Descubrimiento de América, solicita un compendio de textos y una reseña histórica de la poesía de México, desde la Colonia hasta la actualidad, donde ya se destacan los nombres de los modernistas Manuel Gutiérrez Nájera, Salvador Díaz Mirón, Manuel José Othón y Luis G. Urbina. En el año 1914 salió a la luz Las cien mejores poesías (líricas) mexicanas de Antonio Castro Leal, Manuel Toussaint y Alberto Vázquez del Mercado, discípulos de Pedro Henríquez Ureña, y donde el modernismo se destaca con Gutiérrez Nájera como su mayor representante. En 1916, año de la muerte de Rubén Darío, se publicó Poetas nuevos de México de Genaro Estrada: "la primera antología poética nacional del modernismo en el mundo hispánico de carácter crítico" (García Gutiérrez y García Morales: 489). Correspondiente al grupo vanguardista de los Contemporáneos, no podemos dejar de soslayar tres antologías: Antología de poetas modernos de México (1920), Ocho poetas (1923) y Antología de jóvenes poetas mexicanos (1922), que marcan, además, el camino hacia la publicada por Jorge Cuesta en 1928, Antología de la poesía mexicana moderna, y ésta, a su vez, engendra la respuesta estridentista con otra antología en el mismo año: Antología de la poesía moderna. Avanzado el siglo xx, la autoridad intelectual de Octavio Paz se afirma en la edición de varias antologías: Laurel (1941) y Poesía en movimiento (1966), ambas con la participación de José Emilio Pacheco. Para profundizar sobre los aspectos de estos últimos compendios poéticos, consultar: "Tres antologías: la formulación del canon" de Anthony Stanton (1998) y sobre las antologías mexicanas entre 1910 y 1940: "Una historia de las antologías poéticas mexicanas modernas (1910-1940)" de Rosa García Gutiérrez y Alfonso García Morales (2007).

2 Proceso se inició el mismo año en que Octavio Paz fundó Vuelta (1976) y luego de que Excélsior, espacio donde apareció Plural, revista también creada por Paz en 1971, 
Las preguntas que nos planteamos sobre el nuevo recorrido que plantea Pacheco sobre los antepasados del modernismo son: ¿qué figuras literarias mexicanas privilegia para elaborar su red de afiliaciones modernistas?, ¿qué criterios sustentan su selección? Mediante esta producción crítica, ¿José Emilio Pacheco logra el cometido que se propuso, esto es, ofrecer, finalmente, un conjunto de textos característicos del modernismo mexicano? Responder estos interrogantes es nuestra meta y, para ello, además, abordaremos sus reflexiones desplegadas en otros textos, sin embargo, próximos a la Antología del modernismo [1884-1921] en tanto la complementan en varios aspectos. Entre las textualidades subsidiarias más destacadas se presenta otra antología, Poesía modernista. Una antología general, preparada por el mexicano que, si bien abarca el modernismo, no se centra únicamente en las letras de su país, sino en otras que se desplegaron en centros como Nicaragua, Argentina, Cuba, Colombia, Bolivia, Perú y Uruguay. Tanto el repertorio de textos como el prólogo y las notas introductorias a cada uno de los escritores antologados son más concisos y retoman muchas de las ideas desarrolladas en el compendio de 1970, razón por la que esta antología, y no la posterior, funciona como eje rector de este trabajo. ${ }^{3}$ Este corpus se complementa con una serie de notas periodísticas que José Emilio Pacheco publicó en Proceso mediante sus columnas semanales. Recordemos que en su último "Inventario" se refirió al escritor argentino Juan Gelman, fallecido el 14 de enero de $2014 .{ }^{4}$

finalizara abruptamente por el golpe presidencial asestado a la publicación en julio de 1976 (Flores: 30-31).

3 La publicación de Poesía modernista. Una antología general se enmarcó en un proyecto denominado "Clásicos Americanos", impulsado por la Secretaría de Educación Pública y la Universidad Nacional Autónoma de México, para acercar ciertos libros a un público amplio. José Emilio Pacheco fue el elegido para diagramar y organizar la selección referida a la poesía modernista. Los poetas antologados son: José Martí, Salvador Díaz Mirón, Manuel José Othón, Manuel Gutiérrez Nájera, Julián del Casal, José Asunción Silva, Rubén Darío, Ricardo Jaimes Freyre, Amado Nervo, Enrique González Martínez, José Juan Tablada, Guillermo Valencia, Leopoldo Lugones, José María Eguren, José Santos Chocano, Julio Herrera y Reissig, Porfirio Barba Jacob y Delmira Agustini.

4 La trayectoria de José Emilio Pacheco como periodista cultural se inicia en la década de los cincuenta. Su columna "Inventario" la inició en el suplemento Diorama de la Cultura del periódico Excélsior, dirigido por Julio Scherer (Ruiz Abreu 2013 y Karam Cárdenas 2013). 


\section{José Emilio Pacheco: crítico literario}

Desde las primeras páginas de Antología del modernismo [1884-1921] nos topamos con su estructura organizativa que lejos está de presentar esta colección como una yuxtaposición de textos y autores sin referencias. Antes de adentrarnos a una lectura atenta, visualizamos que cada elección está minuciosamente razonada; la inclusión de determinado escritor y de ciertos textos (y no otros) ha sido parte de un proceso meticuloso, complejo, donde las decisiones fueron amparadas por un aparato crítico que se encuentra citado. Pacheco, en tanto lector crítico, que ordena y dispone lo dado, diseñó para modular cada una de sus decisiones una entrada particular que justifica la inserción de los poetas en este nuevo conjunto, además de las notas enumeradas que esclarecen cierto contenido de los poemas seleccionados y las fuentes de las poesías escogidas. ${ }^{5}$

Sobre los criterios explícitos, Pacheco afirma que siguió un orden cronológico (excepto con Manuel Gutiérrez Nájera, que abre la antología); mantiene la integridad textual y no resume ni recorta. Su estrategia está en serle fiel al texto y a su creador; si modifica (tal es el caso de la ortografía y la puntuación según prácticas vigentes en el momento de su trabajo) es bajo la condición de no alterar ni el sentido ni el tono de los versos. Ahora bien, ¿es posible desandar el camino crítico de esta antología?, ¿podemos reconocer en ese recorrido interrelaciones entre los diferentes poetas antologados que definan a Pacheco como crítico comprometido con el pasado de las letras de su país? En síntesis, por qué presenta una antología que, como plantea en el prólogo, se separa del postulado oficial sobre el modernismo. Pacheco pretende releer la tradición modernista y, en esa relectura, sostiene otro recorrido para entenderla ${ }^{6}$. Como también defiende en el prólogo a las Obras completas I de Rubén Darío, el primer paso es tras-

5 En este orden, los poetas antologados son: Tomo I: Manuel Gutiérrez Nájera, Salvador Díaz Mirón, Manuel José Othón, Francisco González León, Francisco A. de Icaza y Luis G. Urbina. Tomo II: Amado Nervo, José Juan Tablada, Enrique González Martínez, María Enriqueta Camarillo de Pereyra, Alfredo R. Placencia, Rafael López, Efrén Rebolledo y Ramón López Velarde.

${ }_{6}$ Cabe señalar que no desconocemos los trabajos de Carmen Alemany Bay, entre ellos, "Elecciones y lecciones poéticas de José Emilio Pacheco (Terrazas, sor Juana, Darío, Lugones y Vallejo)" (2015) y "Acercamientos de José Emilio Pacheco al modernismo 
tocar ciertos principios. En esta nueva interpretación no cabe confundir "precursor" con "iniciador"; el primer término no entiende el modernismo como proceso, continuidad, incesante diálogo. Manuel Gutiérrez Nájera, Salvador Díaz Mirón, José Martí, Julián del Casal y José Asunción Silva son leídos como "iniciadores" en lugar de "precursores" porque "abrieron el camino a Darío, que enlazó esa generación con la siguiente: Leopoldo Lugones, Ricardo Jaime Freyre, Amado Nervo, Guillermo Valencia, José Santos Chocano y los que llegaron después" (38). La perspectiva desde la cual Pacheco lee e interpreta se aleja de las parcialidades, los reduccionismos, para dar lugar a una perspectiva global, que pone en diálogo literaturas de diferentes latitudes, donde la española y la francesa irrumpen con un claro protagonismo.

La tarea de Pacheco se encuentra enmarcada en el proyecto religador y sistematizador que para Susana Zanetti (1994) singulariza al modernismo: ${ }^{7}$ reúne figuras destacadas de las letras mexicanas en una antología y escribe reseñas y notas en columnas periodísticas para acentuar los lazos efectivos que se gestaron en el primer movimiento literario que articuló concretamente artistas de todo el ámbito hispanoamericano y que logró igual proyección en España mediante encuentros, revistas, artículos de unos escritores sobre otros, entre demás operaciones (Zanetti 2008: 523). La articulación no es azarosa, es prolijamente pensada y razonada para ligar

mexicano: de la teoría (ensayo) a la práctica (poema)" (2017), que abordan los vínculos de la poética pachequiana con la tradición literaria del modernismo.

7 Susana Zanetti explica que las religaciones que se comienzan a efectuar a partir del modernismo son gracias a las transformaciones ocurridas desde 1880, aproximadamente, momento en que América Latina se incorpora al proceso de modernización: "El desarrollo económico y social, y sus consecuencias — concentración urbana, nuevos medios de comunicación- proporcionaron condiciones favorables a la irradiación de los logros del campo cultural ampliado, diversificado y complejo que surgía en cada uno de los centros hispanoamericanos, sobre todo en los más modernos; iba quedando atrás, siempre en términos relativos, una comunidad letrada de incidencia precaria, restringida en sus alcances continentales por la incomunicación y la distancia. El proceso modernizador no determinó la constelación de artistas e intelectuales del período, pero fue condición imprescindible para que fuera posible un movimiento mancomunado en concepciones estéticas e ideológicas, para que surgiera el intercambio y la discusión entre pares, medianamente generalizada y con cierta simultaneidad. La religación, en sus numerosas variables, supone la quiebra del aislamiento, del compartimento estanco, y para ello hacían falta bases materiales para vehiculizarlas y una mentalidad moderna" (1994: 500). 
un legado que, como también dice Zanetti, opera en "ciertas metrópolis, determinados textos y figuras" (1994: 491) y que, indefectiblemente, conduce a reconstruir esa parte del objeto literatura latinoamericana.

Manuel Gutiérrez Nájera es el primer poeta de la compilación y es la excepción a uno de los criterios que sostiene Pacheco. Una peculiaridad recuperada es que Gutiérrez Nájera "nunca fue enviado a la escuela" (Pacheco 1970: 3). Su primera conjetura es que sus padres no querían que su hijo se contaminara con las ideas positivistas. Más allá de que dicha presunción sea falsa o verdadera, plasma las particularidades de un mundo letrado que está atravesado por transformaciones radicales y donde la formación no necesariamente se ajustaba a ciertas instituciones, como la escuela o la universidad. Esta apreciación sobre Gutiérrez Nájera se complementa, además, con el hecho de que su educación estuvo a cargo de profesores particulares, quienes "le enseñaron idiomas y otras materias" (1970: 3) y con su sostenido interés por la escritura y la lectura que, según entiende Pacheco, fue inherente en Gutiérrez Nájera desde el momento en que aprendió el castellano literario a partir de los místicos del siglo xvı. Por lo tanto, sus inicios literarios se enmarcan en una alfabetización que, además de asemejarse a la de otros modernistas cuyas primeras lecturas provenían de bibliotecas provincianas (por ejemplo, Rubén Darío), pretendía, desde sus inicios, extender los límites culturales nacionales. Esta situación adquiere mayor envergadura cuando el modernista mexicano decide fundar, junto con Carlos Díaz Dufoo, la Revista Azul (1894-1896), "primer núcleo del modernismo mexicano en que aparecieron juntos autores de Europa e Hispanoamérica, los viejos maestros y los escritores que comenzaban" (3-4). ${ }^{8}$ El foco de interés de las primeras líneas dedicadas a Gutiérrez Nájera es desplegar las cualidades de un escritor preocupado por la difusión de las letras de su país, así como por la recepción de las lecturas extranjeras, aunque esto le haya valido ciertas rispideces con la naciente burguesía mexicana (4).

\footnotetext{
8 Hacia el año 1894 surgen numerosas revistas con tendencias modernistas en Hispanoamérica. Entre ellas, podemos mencionar: Cosmópolis y El Cojo Ilustrado en Caracas, El Iris en Lima, Revista de América en Buenos Aires, El Mundo en México y la Revista Gris en Bogotá (Pineda Franco 1998).
} 
En Gutiérrez Nájera (y aquí nuestra hipótesis sobre la alteración cronológica efectuada en la antología) se reúnen una serie de cualidades que señalan su presencia axial en el modernismo mexicano; éstas marcan una nueva manera de entender y hacer literatura; el poeta supo reelaborar el legado literario previo (porque continúa la línea trazada por Ignacio Manuel Altamirano y Luis G. Ortiz) e influir en los usos estéticos de la lengua posterior. Gutiérrez Nájera ocupa un lugar especial y la pregunta es: ipor qué Pacheco lo eligió a él para inaugurar su antología? Pues porque, además de ser uno de los iniciadores del modernismo desde la publicación de "La Duquesa Job" (1884), "su mejor poema y el primer augurio firme del Modernismo que se da en México" $(6)^{9}$, fragua una tradición literaria que rasga los límites nacionales. Pacheco señala su inserción en una tradición más bien latinoamericana al ligarlo con dos de sus figuras emblemáticas, José Martí y Rubén Darío, quienes encarnan el cambio del intelectual decimonónico: del privilegio de lo político (en el caso de Martí) a la afirmación de la autonomía y el saber del arte (en el caso de Darío) (Zanetti 2008: $523)^{10}$. Pacheco retoma esta premisa en un artículo publicado en Letras Libres en el año 2000, donde repasa la serie de descubrimientos literarios promovidos por el literato mexicano. Bajo el rasgo sobresaliente de la innovación que, como ya adelantamos, procura distanciar de la cualidad de precursor, José Emilio Pacheco subraya momentos axiales de la poética de este escritor que nos permiten comprender su inserción (y su posición inicial) en la antología ${ }^{11}$. Previamente al artículo del 2000 y con posterio-

9 Los números arábigos y romanos corresponden al propio sistema de Pacheco.

10 Este perfil político es lo que, según Pacheco, también diferencia a José Martí del resto de los modernistas: "No resulta menor paradoja modernista que Martí sea una figura a la vez central y excéntrica en el movimiento que inició. Martí vive por y para la independencia de su patria todavía perteneciente al imperio español. Lucha por la revolución social en tanto que los demás sólo se preocupan por la renovación literaria" (1982b).

11 Con motivo de una reseña sobre Exposición documental de Manuel Gutiérrez Nájera de Ernesto Mejía, publicada en la Revista de la Universidad de México, José Emilio Pacheco ya había registrado, diez años antes de la antología sobre el modernismo mexicano, la cualidad innovadora de la labor literaria de Gutiérrez Nájera y en el artículo publicado en Letras Libres también asume el modernismo como un colectivo, más que como una estética que tiene como referencia, únicamente, una individualidad (como puede ser el caso ya dicho de Rubén Darío). 
ridad a la antología, Pacheco escribe en Proceso una nota cuyo punto de partida es el centenario del modernismo. Aquí reitera su distanciamiento de la definición del modernismo: "igual a Darío, Prosas profanas, cisnes, joyas, princesas, jardines versallescos, evasión de la realidad hispanoamericana, arte por el arte, versos sonoros, festivales escolares" (1982b); ${ }^{12}$ alude a la amistad entre Martí y Gutiérrez Nájera como una bisagra en la conformación estética de los últimos años del siglo XIx y los primeros del xx. Durante la modernización, tal como expresa Ángel Rama, se alcanzó algo que nunca antes había sucedido que es "la intercomunicación interna de la producción literaria de las diversas áreas hispanohablantes, a la que escasamente comenzó a vincularse Brasil" (1983: 8). En este sentido, los lazos entre los escritores-artistas, favorecidos por los medios de comunicación moderna (diarios, agencias noticiosas, redes de cables submarinos, telégrafos, etc.), cumplieron una función religadora de envergadura; los intelectuales se esforzaron para saber lo que realizaban sus colegas en otros puntos del continente (8). Las caminatas cotidianas compartidas por Martí y Gutiérrez Nájera, posiblemente, servían para intercambiar lecturas y conocer nuevas propuestas estéticas y se complementaban con otros modos de circulación y socialización de los materiales característicos de la época, como los viajes propios o de amigos y las permutas de libros y revistas extranjeras generadas en las redacciones de los diarios o en algún café. Pacheco, en el prólogo del libro Modernismo. Supuestos históricos y culturales de Rafael Gutiérrez Girardot, también se detiene en estos nuevos espacios de socialización y difusión literaria:

Tampoco parece claro de qué manera libros tan influyentes como Prosas profanas, Cantos de vida y esperanza o Lunario sentimental se publicaron en ediciones de sólo 500 ejemplares y tardaron años en agotarse. Y es que hubo otras

12 Pacheco también se distancia de las afirmaciones críticas que se sostienen solamente en las obras canónicas de Rubén Darío, como el caso de Prosas profanas, o bien, que aseguran que luego de Cantos de vida y esperanza (1905) el nicaragüense ingresa a una "decadencia irrefrenable" (1978). En su afán de rever lo escrito y leído sobre el modernismo, rescata composiciones poéticas soslayadas por la crítica literaria del momento. Es el caso del poema "Armonía", una de las producciones finales, omitido por el propio Darío en Canto a la Argentina y otros poemas (1914) y por los editores que lo consideran "apenas una variante o un resumen de su soneto ocasional a Nervo" (1978). Sin embargo Pacheco lo define, en su brevedad, "una obra-maestra" (1978). 
formas de difusión de la poesía que ahora ya no existen: las columnas de los diarios, los almanaques, las recitaciones, los tomos de lecturas escolares (2004: 17-18).

Además, se refiere a las continuas estadías de los escritores en otras ciudades, ya sean latinoamericanas o europeas que también fueron un importante elemento religador (Rama 1983 y 1985b; Zanetti 1994 y 2008). En el caso de Martí, su destierro a España en 1870 puede entenderse como un momento clave en su carrera profesional y política, ya que es allí donde estudia las carreras de Letras y Derecho (Colombi: 9) y donde el advenimiento de la Primera República española (1873) reaviva el deseo de libertad de su Cuba querida (Serna Arnáiz: 18). Sus estancias en París despertaron, además de su entusiasmo por la actriz Sarah Bernhardt (Valdés 2008), el interés por escritores como Gustave Flaubert y Víctor Hugo, ${ }^{13}$ entre otros.

Lector y ágil autor de crónicas, Gutiérrez Nájera es, además del primer escritor "profesional" (1970: 3), ${ }^{14}$ el autor de Por donde se sube al cielo (1882), novela que no sólo inicia el modernismo hispanoamericano, sino que es anterior a Amistad funesta (1885) de Martí y a los cuentos incluidos por Darío en Azul (1888) (Pacheco 2000: 20). ${ }^{15}$ Pacheco continúa

13 Recordemos que José Martí realizó la traducción de Mis hijos de Víctor Hugo y la publicó en forma de folletín en la Revista Universal de México. Para una mayor profundización sobre este tema, consultar el trabajo "Mis hijos de Víctor Hugo, en la traducción de José Martí (1875)" de Carmen Suárez de León (2012).

14 Tal como afirman Ángel Rama y Julio Ramos, el campo de profesionalización y autonomía de los escritores es bastante relativo hacia fines del siglo xIx y principios del xx. Todavía necesitan de la prensa no solamente como medio de subsistencia sino como posibilidad de fundar, desde allí, un nuevo lugar de enunciación y legitimidad (Rama 1970: 67-79 y Ramos 2003: 86). Ramos señala, además, que, a pesar de que la incorporación al mercado de bienes culturales se sistematiza a fin de siglo, la presencia de escritores en el periodismo no es una particularidad exclusiva de los modernistas. Ya en las primeras décadas del siglo xIx José Joaquín Fernández de Lizardi o Hilario Ascasubi vivían de lo que escribían en los periódicos (64-65).

15 En la antología dedicada al modernismo hispanoamericano, Pacheco también indica como fecha de su inicio el año 1882 porque es el año en que Martí comienza sus "Cartas" desde Nueva York, publica Ismaelillo y una crónica sobre una conferencia de Oscar Wilde que, según nuestro autor, es un esbozo de manifiesto del modernismo: "Vivimos, los que hablamos lengua castellana, Ilenos todos de Horacio y de Virgilio, y parece que las fronteras de nuestro espíritu son las de nuestro lenguaje. ¿Por qué nos 
honrando a Gutiérrez Nájera al señalarlo como "el más importante crítico teatral de su tiempo mexicano" (2000: 21) y al ubicar la prosa de la novela referida en un lugar excelso: "La prosa de Por donde se sube al cielo no admite comparación con nada de lo que se escribía por entonces en México" (21). Sus innovaciones estilísticas, además, se sostienen en el contexto mexicano: "Ilevó a su perfección la crónica de estilo parisino en que lo antecedieron Altamirano y Luis G. Ortiz y lo reemplazaron Urbina, Nervo, Tablada, Rafael López y Ramón López Velarde" (1970: 4). En el caso de Urbina, Pacheco retoma este linaje de la crónica mexicana al resaltar al autor de "Elegía del retorno" como uno de los fundadores de la crónica cinematográfica en lengua española a partir de las reseñas que escribió para diferentes periódicos, como El Imparcial y El Mundo Ilustrado (108). La relación Urbina-Gutiérrez Nájera se reanuda en el momento de destacar sus cualidades críticas que, junto con sus aptitudes literarias, lo salvaron de ser un "simple epígono" (109).

Pacheco, lector y crítico, diseña una red de relaciones que se complementan con el resto de las entradas dedicadas a los otros escritores antologados. De esta manera, sus afirmaciones sobre Gutiérrez Nájera se integran con las que aparecen respecto a los otros autores, lo cual enaltece aún más la figura de éste. Así, Nervo (quien abre el segundo tomo de la colección) es "el punto intermedio entre el afán renovador de Manuel Gutiérrez Nájera y la plenitud de Ramón López Velarde" (1970: 3) y Luis G. Urbina "un crítico tan generoso como Gutiérrez Nájera" (109). El gesto discursivo de Pacheco es ponerlos en diálogo, ubicarlos en una red de reciprocidades e intercambios para justificar la tradición que pretende defender. En el caso de Nervo, Pacheco explicita que su admiración hacia Gutiérrez Nájera lo estimula a trasladarse desde Mazatlán a la Ciudad de México para integrarse a la Revista Azul. De este modo, claramente se plasma la preeminencia que adquieren determinados centros, como México, en la formación intelectual de los modernistas, sostenida, como observamos,

han de ser fruta casi vedada las literaturas extranjeras, tan sobradas hoy de ese ambiente natural, fuerza sincera y espíritu actual que falta en la literatura española?... Conocer diversas literaturas es el mejor medio de liberarse de la tiranía de algunas de ellas" (Martí ápud Pacheco 1982a: 11). 
por el "espíritu de cofradía" que define al movimiento ${ }^{16}$ (Zanetti 1994: 492). Pacheco resalta las cualidades narrativas de Nervo, quien dueño de "un gran don para contar y una prosa de simplicidad y fluidez" (1970: 1) se destaca entre quienes fueron sus contemporáneos, por ejemplo, el novelista Federico Gamboa. También le concede un lugar sobresaliente al señalarlo como el iniciador de la corriente fantástica en la literatura mexicana a partir de su relato "La última guerra", incluido en Almas que pasan (1906). Así como Pacheco resalta las cualidades estéticas de este poeta, no deja de mencionar las actividades oficiales y diplomáticas que Nervo desarrolló en el exterior y que, en lugar de mantenerlo aislado y relegado del mundo de las letras, lo condujeron a la realización de actividades literarias y críticas diversas. ${ }^{17}$ La intención de Pacheco es revalorizar a Nervo, reubicarlo entre los escritores modernistas célebres, aspecto que en el momento de publicación de la antología ocurría de manera esporádica. ${ }^{18} \mathrm{Se}$ distancia de aquellas posturas que hacia 1950 descendieron a Nervo "a su punto más bajo" (1970: 3) y, asimismo, distingue los distanciamientos, innecesarios, que la crítica de los primeros años del siglo xx erigía con aqueIlos escritores que obtenían un respaldo popular, argumento refutado al afiliarlo con escritores de otras tradiciones literarias de envergadura, como la estadounidense y la francesa. Como ya ha adelantado en su prólogo, Pacheco resalta las cualidades innovadoras que se gestan en el lenguaje del novecientos. Nervo se presenta "decidido a hallar ritmos que se aparten

16 No podemos dejar de soslayar el lugar preeminente que adquiere el periodismo durante este momento, particularmente porque, como en el caso de Nervo, ingresa a ese medio muy joven para cubrir las necesidades de su familia, conformada por su madre y cuatro hermanos menores (su padre había fallecido cuando Nervo tenía trece años) (Pacheco 1970: 1). Tal como deja entrever Pacheco, trabajar como cronista de sociales en El Correo de la Tarde, como redactor de El Universal, El Nacional y El Mundo no sólo le permitió acceder a un salario, sino establecer amistades literarias como la que mantendrá con Darío en su viaje a Francia para reseñar la Exposición Universal de París.

17 Aquí se afianza la tesis de Susana Zanetti sobre la importancia de España como centro religador, como lugar donde durante el período que nos preocupa "se estrechan relaciones y reconocimientos mutuos de una envergadura inédita luego de la independencia americana" (1994: 527).

18 Pacheco indica dos episodios que motivaron el rescate de Amado Nervo, cercanos a la publicación de la antología: el libro Genio y figura de Amado Nervo (1968) de Manuel Durán y un homenaje en el cincuentenario de su muerte. 
de las normas académicas y expresen la nueva sensibilidad" (3). Pondera la posibilidad de convertir todo en poesía, su trabajo estético se condensa en el fluir de las palabras de quien "no escribe con un vocabulario sino con todo el lenguaje" (4).

Mediante un ejercicio crítico que parece responder al postulado de Roland Barthes sobre los usos y los modos propios de la ficción en la crítica literaria, José Emilio Pacheco renuncia a la falsa objetividad del lenguaje para sumergirse en el universo ficcional, pero no como "objeto de análisis sino como actividad de escritura" (Barthes: 17). De este modo, Pacheco honra a la literatura aun cuando su lugar de enunciación es el de crítico; se sumerge en la imaginación, mediante la creación de una conversación entre Nervo y López Velarde ya muertos, y pone a su disposición las cualidades de la literatura. El encuentro muestra a los dos personajes sosteniendo la antología Asamblea de jóvenes poetas de México, publicada por Gabriel Zaid en 1980. La creación ficcional se impregna de afirmaciones que sitúan a ambos poetas en la generación modernista que renovó el lenguaje estético. Sobre las calles de un México diferente al que ellos conocieron, López Velarde dice: "No hay una sola de las veinticuatro horas en que Madero no conozca mi pisada. Fue una calle, luego una rue y ahora es una street" (1980b), mientras reflexiona junto con su compañero sobre el hecho poético y sobre cómo sobrevivir, a través de sus poesías, al irrevocable fluir del tiempo. La colección de Zaid opera como excusa, como pretexto para que Nervo, distanciándose de López Velarde, apueste a una poesía que, como la defendida por Pacheco en el prólogo de su antología, sea colectiva, donde lo que prime sea el texto y no quién la escribió: "una poesía de todos y para todos en que desaparecen los nombres y sólo cuentan los poemas. Lo que importa es el texto: saber quién lo escribió es algo enteramente secundario" (1980b). Lo que pareció un simple encuentro entre viejos amigos se constituye en un análisis del México actual, tan distante del que ellos conocieron y vivieron. El ineludible paso del tiempo, tópico reiterado en la poética de José Emilio Pacheco, reaparece en la charla de estos dos poetas, ahora personajes de la ficción pachequiana. El interrogante principal que ambos debaten es: ¿qué es la poesía en un mundo en constante transformación? Frente a la postura conservadora de López Velarde, quien decreta la muerte de la poesía con el libro de Zaid, 
Nervo mantiene la esperanza de que la poesía sobreviva a los tumultuosos cambios y no se ciña a lo que solamente se escribió en el pasado; la poesía entendida no como el bien preciado de unos pocos, sino como expresión viva, como patrimonio de todos. El compendio de Zaid, desde la postura de Nervo, confirma su posición sobre la posibilidad de escribir buena poesía, aun cuando las condiciones culturales difieren de las del principio del siglo xx, cuando tanto Nervo como López Velarde desconocían el alcance que iba a tener su trabajo en la lengua poética.

Las interrelaciones entre poetas constituyen la acción discursiva a la que recurre Pacheco para explicitar una tradición modernista mexicana y, aunque no sea enunciada en el prólogo, se reconstruye, como ya expresamos, al reanudar el recorrido de este repertorio poético. Es una operación que marca comparaciones para resaltar las cualidades de uno u otro poeta, tal como lo hace al momento de comparar a López Velarde con Nervo y Gutiérrez Nájera para enaltecer el legado del primero:

López Velarde presenta una pluralidad de alusiones, reticencias, elipsis, sobreentendidos y significados subtextuales que no hay en ninguno de sus antecesores. El conflicto de base no es distinto al de Nájera ni al de Nervo ("nuestra única grandeza moral consiste en la pugna que nos roe las entrañas"), pero sus dones poéticos y su voluntad de estilo son mucho mayores y añade a su innata sabiduría verbal la de quienes lo antecedieron. Con la pugna entre carne y espíritu aquéllos hicieron casi siempre retórica: López Velarde hizo casi siempre poesía (1970: 129).

Como observamos, Pacheco ubica a López Velarde en un lugar superior al de los otros dos poetas y esta posición se consolida en los artículos que tienen el propósito de apartar esta figura poética del lugar estanco de "poeta de provincia" que advierte en la teoría modernista "oficial". En este sentido, resulta indispensable atender al conjunto de crónicas y ensayos reunidos en el libro Ramón López Velarde: la lumbre inmóvil, publicado en 2003. ${ }^{19}$ Este compendio y la antología de 1970 afirman la admiración

19 Más allá de que esta compilación data de 2003, su contenido principia en 1970 y termina hasta, aproximadamente, fines de la década del ochenta. Sin embargo, se incluyen textos que, si bien sus primeras versiones pertenecen a las fechas señaladas, el escritor mexicano los ha reescrito posteriormente. Esto da cuenta de la continuidad 
de Pacheco por el recordado poeta nacional a la vez que abonan el propósito de elaborar y definir una tradición del modernismo mexicano. ${ }^{20}$ Pierre Bourdieu, asimismo, ya había argumentado que la mayoría de las obras artísticas contienen indicaciones sobre las representaciones que el autor se hace de su empresa, sobre los conceptos en los cuales imaginó su originalidad y su novedad, es decir, sobre aquello que lo distingue de sus contemporáneos y sus predecesores (cfr. 1971: 148). Pacheco, en efecto, reconoce en la crítica y en la antología los espacios propicios para desmontar ciertas construcciones textuales que se han elaborado alrededor de López Velarde que, en vez de dar cuenta de una auténtica imagen del escritor, lo reducen a explicaciones simplistas. La nota que antecede la selección de textos de López Velarde en la Antología del modernismo es la que se reproduce en 2003 bajo el título de "Ramón López Velarde y la posesión por pérdida". El propósito es revertir la postura de que su estética no pertenece al modernismo para, por el contrario, aseverar que es uno de los mayores poetas que tuvo dicha corriente renovadora de los valores estéticos. Ya desde el inicio de la presentación, la intención es reconocerlo como par de otros modernistas. Ahora bien, ¿cuál es el argumento sostenido por Pacheco para mantener dicha afirmación? La respuesta se desprende de la revolución que López Velarde ejerció en el plano lingüístico, específicamente, en la exploración "hasta el delirio de las posibilidades de la rima" (1988: 3). Este elemento, cabe agregar, había sido señalado como central en 1970: "En todo caso se parece más a los escritores del novecientos que a los vanguardistas de los veinte, quienes en primer término abandonan la rima, elemento esencial en López Velarde" (128). Al mismo tiempo, se amplían las correspondencias que se pueden reconocer entre el poeta mexicano y otros escritores, como Franz Kafka, T. S. Eliot, Jules Laforgue y Charles Baudelaire. En 1987 Pacheco reafirma las afiliaciones entre López Velarde y el poeta Jules Laforgue en un "Inventario" que se abre con el protagonismo del francés en la última fase del modernismo hispánico. La tradición literaria se entiende como un entramado de voces

en nudos de interés por parte de José Emilio Pacheco, que nunca abandona y siempre retoma, como es el caso de la figura de Ramón López Velarde.

20 Ramón López Velarde fue laureado como poeta nacional por el presidente Luis Echeverría Álvarez en 1971. 
plurales en cuya multiplicidad se reconocen afinidades y afiliaciones estéticas ineludibles.

La preocupación de Pacheco por incluir a López Velarde en una tradición literaria universal que, en términos de Said (1978: 13), puede indicar la inauguración de una producción de significados otra que reclama un status, en este caso, el status correspondiente a la obra de López Velarde, junto con otras obras que, en efecto, proponen una diferencia y una nueva manera de leer y entender la obra del autor de El son del corazón. La posición cuestionadora de Pacheco sobre lo establecido resurge cuando leemos otro de los textos complementarios, focalizado en "La suave Patria", oficialmente leído como el poema épico de la Revolución mexicana. Frente a esta interpretación, Pacheco propone otra que no está circunscripta sólo a la materia política, sino al pasado y a la memoria (tópicos reincidentes en la poética pachequiana): "quiso al mismo tiempo conmemorar el primer siglo de México independiente (1821) [y] lamentar el cuarto centenario de la caída de Tenochtitlan (1521)" (2003: 18). De este modo, Pacheco opta por una interpretación que se aleja notablemente de la lectura nacionalista que, a lo largo de los años, se ha perpetuado sobre esta producción literaria. Su postura como crítico le permite "desestabilizar" la lectura oficial para dar cauce a su propia interpretación, anclada en la trascendencia del poema por su valor artístico más que por las connotaciones políticas que desde el Estado se le otorgó. Datos de índole histórica le sirven a Pacheco para justificar su postura: en 1921, año de la escritura del poema y de la muerte de su autor, recién se iniciaba la llamada "etapa constructiva" posrevolucionaria y el poeta apenas fue testigo de la guerra civil entre las facciones que se disputaban el poder. Por lo tanto, la decisión estatal de imprimirle un sentido político al poema queda notablemente develada. Además, el poema se caracteriza por "poetizar sus diarias sensaciones y reflexiones sobre la realidad íntima, no histórica ni política, del país" (18). "La suave Patria" propone un regreso a la tierra, a la infancia como refugio de la modernización e industrialización que, en ese momento, estaba comenzando a sufrir México. La Patria, entonces, se identifica con la protección, con el viaje de regreso a la vida anterior, pueblerina, que niega el progreso y el nuevo estilo de la ciudad. Esta lectura "perturbadora" se extiende a otro aspecto que es el de los modos de 
leer la obra velardiana que, a su vez, deja vislumbrar una posible teoría sobre la lectura defendida por Pacheco en varios momentos de su producción crítica, no sólo en sus ensayos sino en su literatura. En la crónica "Las alusiones perdidas (para un glosario de López Velarde)", fechada el 27 de junio de 1988, se resiste a la "lectura ortopédica" que consiste en restituir meticulosamente cada uno de los significados que presenta una producción literaria. Así, expresa Pacheco, apelar a este tipo de interpretaciones inhabilita la posibilidad de encontrar otros sentidos al texto poético y, de este modo, menosprecia la reinvención que el lector puede realizar en su encuentro con el texto literario. "La prisionera del Valle de México", otro de los ensayos incluidos en Ramón López Velarde: la lumbre inmóvil, corresponde a una crónica que se estructura a partir de un yo, que identificamos como el propio José Emilio Pacheco, y un tú, Ramón López Velarde. En efecto, esta operación narrativa que imagina un posible diálogo entre el crítico y uno de sus poetas predilectos muestra que el único contacto que puede establecer un lector con un autor es a través de sus textos porque la verdadera voz es la que escuchamos por dentro, en los poemas (2003: 83). La lectura siempre implica una relectura y una recreación del texto que imposibilita que éste se clausure en un único significado, como ocurre con la obra de López Velarde. Los misterios que despierta toda obra literaria de envergadura, como dice Pacheco respecto a "La suave Patria", nunca se agotan e invitan a toda clase de interpretaciones (119).

Si reanudamos el sendero proyectado por la antología modernista, la incorporación de José Juan Tablada reafirma la admiración de Pacheco hacia López Velarde, cuya escritura, además, influirá parte de la trayectoria literaria de Rafael López. La admiración de este último por Nervo, Darío y el Santos Chocano de Alma América lo estimularon a buscar temas en la historia mexicana (Pacheco 1970: 105). Entre López Velarde y Tablada hay puntos de encuentro que avanzan sobre la configuración cultural propuesta por Pacheco: "López Velarde cierra espléndidamente el modernismo mexicano y, al mismo tiempo que Tablada, lo convierte en modernidad, piedra de fundación de nuestra poesía contemporánea" (1970: 128). ${ }^{21}$

21 Recordemos que Tablada fue uno de los fundadores de la Revista Moderna y también participó en la Revista Azul, de Gutiérrez Nájera y Díaz Dufoo. Justamente en esa revista es donde publicó el poema "Ónix". 
Estas últimas ideas se integran con la estampa dedicada a Tablada que, como en el caso de López Velarde, algunos de sus escritos vislumbran el ocaso de la estética modernista: “'Los pijijes' y 'Quinta Avenida' ya anuncian la modificación que está a punto de operarse en Tablada. Capta en el aire la muerte del modernismo y se adelanta a los jóvenes en iniciar nuestra vanguardia, como una consecuencia natural (necesaria) del movimiento anterior" (31). Sin embargo, Tablada también es reconocido como el iniciador del movimiento simbolista o decadente en México a partir de la notoriedad que alcanzó con el poema "Ónix".

Pacheco resalta cómo los viajes por motivos políticos le proveyeron a Tablada nuevas relaciones literarias. ${ }^{22}$ Así, por ejemplo, el viaje en 1900 a Japón le facilitó la realización de traducciones hispanoamericanas de autores de dicho país y la estadía en Nueva York le concedió la oportunidad de escribir "sobre el arte precortesiano y la nueva pintura (de Rivera a Tamayo)" (1970: 30).

Estos desplazamientos, además de enriquecer su propia estética, significaron, agrega Pacheco, "grandes oportunidades para la poesía de nuestra lengua: en contacto con las vanguardias (los caligramas de Apollinaire, los imaginistas norteamericanos), Tablada publicó poesía ideogramática y su genial adaptación del haikú a la índole del español" (1982a: 141). No podemos dejar de destacar la afiliación que sustenta Pacheco al ubicar a Tablada como estímulo de una de las vertientes que tendrá la vanguardia mexicana en los años posteriores, el grupo de "Los Contemporáneos":

Humor y piedad, ternura y precisión gráfica, el gusto por el laconismo del epigrama, un oído bien adiestrado por las libertades modernistas, permitieron a Tablada escribir estos poemas concisos y perfectos que resultaron decisivos para los "Contemporáneos", no como ejemplo sino como estímulo (1970: 31).

22 José Juan Tablada fue un firme opositor a Francisco Madero y colaboró para el gobierno de Victoriano Huerta. Vivió exiliado en Nueva York hasta que en 1918 Carranza indultó a los escritores huertistas y nombró al propio Tablada secretario de la representación mexicana en Caracas y Bogotá (Pacheco 1970: 30). En relación con este aspecto de la vida de Tablada, Pacheco escribe un "Inventario" en el número 308 de Proceso donde deja al descubierto su perfil político conservador. Si bien reconoce sus cualidades en el plano de lo poético, se distancia fervientemente de sus posiciones políticas y rechaza la prosa periodística plasmada en la columna "Tiros al blanco" (EI Imparcial). 
De este modo, si repasamos estas primeras intervenciones, reconocemos en el modernismo mexicano una pieza fundamental (y fundacional): Gutiérrez Nájera, y dos que lo clausuran y ceden su lugar a las innovaciones vanguardistas: Ramón López Velarde y José Juan Tablada. Amado Nervo también conforma este escenario literario porque, como vimos, Pacheco lo señala como uno de los exponentes de esta estética.

Alrededor de estos tres escritores se urden los enlaces con los otros. De una u otra manera, Gutiérrez Nájera, López Velarde y Tablada reaparecen cuando se describen las características literarias del resto de los modernistas mexicanos. Así, cuando es el turno de Manuel José Othón, exigente y obstinado con su estilo, López Velarde vuelve para, indirectamente, consagrarlo como uno de los grandes modernistas. Al mismo tiempo que se resaltan las cualidades literarias de Othón, particularmente de "Idilio salvaje", López Velarde es definido como el heredero de la intensidad poética plasmada en dicha expresión lírica. Ramón López Velarde no se oculta en el discurrir de los otros poetas y es, también, quien salva del olvido a Francisco González León, otro de los modernistas recuperados. Las relaciones, no obstante, son recíprocas; González León también instruyó a López Velarde "a ver la provincia como material artístico, a sentirla en sus perfiles literarios y le suministró al mismo tiempo determinadas formas de expresión: metro, imágenes, adjetivos, formas verbales" (1970: 31). La pretensión de Pacheco es apartarlo del mote oficial de "poeta de provincia" y afiliarlo, en consecuencia, con otras tradiciones que articulan legados y lazos concretos con, en este caso, la literatura francesa y la belga, con lo cual refuerza la apertura hacia otras literaturas que distinguió al modernismo.

Mediante la lectura de cada una de las entradas que Pacheco escribió para presentar a estos poetas se identifican, como expresamos, ciertos cuestionamientos sobre lo que se admite como modernismo. Así, en el caso de Enrique González Martínez, Pacheco rechaza las posturas que aseguran que el soneto "Tuércele el cuello al cisne" (Los senderos ocultos, 1911) es un "manifiesto literario antimodernista" (64). A través de refutaciones razonadas, Pacheco acentúa las falencias de una tradición que ve en González Martínez un opositor irreversible y pretende matizar posiciones estéticas: 
En efecto González Martínez se apartó del esteticismo modernista, pero no antes que Darío y Nervo. Sus versos buscaban — dice él mismo- "el culto al silencio, el ansia de comunidad con la naturaleza, el espíritu de contemplación y la angustia interrogante frente al misterio de la vida".

Ninguno de estos propósitos era ajeno al modernismo. Lo que hizo González Martínez fue subrayar los elementos simbolistas en detrimento de los rasgos parnasianos que prevalecieron en la etapa anterior (65).

En la presentación que hace de él en la antología de 1982 regresa sobre este aspecto de la siguiente manera:

Así, "La muerte del cisne", el soneto que escribió en 1911 no fue la oración fúnebre del modernismo ni, mucho menos, un ataque a Rubén Darío. Simplemente González Martínez protestó contra la "exterioridad y el procedimiento". Es decir, contra los rasgos parnasianos y optó, como su naturaleza se lo pedía, por los simbolistas a quienes tradujo magistralmente (Jardines de Francia, 1915) (1982a: 133).

En esta revisión, Pacheco pretende desmontar la figura de González Martínez como "ángel exterminador" para insistir en que los rasgos señalados también eran propios de otros poetas, contemporáneos a él, como Nervo, y sobresalientes del modernismo mexicano: "Para 1911 ya Nervo había torcido el cuello al cisne o a la elocuencia o al cisne de la elocuencia, y abierto un camino de aspiración a la serenidad resignada. Onís observa que esto es un rasgo mexicano — de raíz indígena- inconcebible en, por ejemplo, Unamuno cuya lucha es de signo inverso: precisamente no resignarse" (1970: 65). No deja de observar así la proyección del autor de Los senderos ocultos (1911) sobre la generación inmediatamente posterior, los Contemporáneos, que también es determinante en la configuración de la tradición cultural que traza José Emilio Pacheco.

El gesto de Pacheco es de rescate y de valoración hacia figuras que aún no tienen el reconocimiento deseado, o bien, que han sido reunidos en pocas oportunidades. Este es el caso de la única mujer que aparece en la antología: María Enriqueta Camarillo de Pereyra, quien, previamente, aparece en la antología Poetas nuevos de México (1914) de Genaro Estrada. Sin titubeos, Pacheco afirma: "es María Enriqueta uno de los artistas más singulares" (90). Aquí también notamos cómo Pacheco se interesa por 
crear nexos entre los poetas merecedores de un lugar en la historia del modernismo mexicano. La autora de Rumores de mi huerto (1908) es emparentada con Francisco A. de Icaza por la textura verbal y las preferencias rítmicas de sus versos (89) así como también con Gustavo Adolfo Bécquer; esta última afiliación permite a Pacheco reiterar su recurso de extender los diálogos entre América y Europa para interpretar mejor una estética que, como ya hemos dicho, "continentalizó", mediante la apropiación, los bienes culturales extranjeros. Las reciprocidades ya habían sido remarcadas en el tomo I donde aparece Icaza; en efecto, la intención de Pacheco es definir con rigor una tradición que enlace de forma precisa cada una de las voces insoslayables.

Francisco de Icaza, cabe señalar, nunca asistió, como el caso de Manuel Gutiérrez Nájera, a la escuela. Su formación estuvo a cargo de su padre y la nota sobresaliente que recae sobre este poeta que gestó una "andanada contra el Establishment español" (100; cursiva en el original) ${ }^{23}$ es su ligazón con la tradición alemana: "Fue uno de los raros escritores hispanoamericanos que conocieron a fondo la cultura germánica: autor de un estudio sobre La Universidad alemana (1916), tradujo poemas de Nietzsche, Liliencron, Dehmel, y aforismos tomados del Diario de Hebbel" (101).

El interés de Pacheco también se posa sobre Alfredo R. Placencia. Lejos, repetimos, de entender el modernismo como manifestación de individualidades, el gesto crítico de Pacheco es vincular, interrelacionar, establecer diálogos y puntos de contacto entre cada una de las especificidades estéticas de los poetas. Frases concisas, pero exactas discurren entre las descripciones pachequianas que, al articular semejanzas, enuncian un modo de entender la literatura latinoamericana en general:

Se parece a Nervo y González Martínez en la aspiración al estoicismo. Como Othón sólo habló de lo que veía y vivía. Al repetir las lamentaciones de Job en la lengua del campo mexicano, Placencia no intentó remedar a los místicos sino hablar a Dios de frente con ellos. Quizá por esto Placencia es, antes de Carlos Pellicer, nuestro mejor poeta católico (97).

23 Aquí Pacheco se refiere a Examen de críticos, publicado en 1894, donde Icaza censuró a Marcelino Menéndez Pelayo, Juan Valera y Emilia Pardo Bazán. 
Efrén Rebolledo también surge entre los autores seleccionados por Pacheco y merece su asombro por poder "individualizarse dentro de la corriente de moda" (1970: 114). Citar, distanciarse de lo ya dicho y reformular son otras de las estrategias que emplea para presentar a un poeta que, siete años después, será objeto de estudio en una de las notas de Proceso por su novela Salamandra (1919). ${ }^{24}$

Pacheco se separa de los lugares comunes, de ciertas afirmaciones que anquilosan figuras literarias como la de Rebolledo. Así, niega un juicio de Amado Nervo, "más bien alto artífice que alto poeta" (1970: 114), que se convirtió en "lugar endémico de nuestra historiografía" (114) y determinó la omisión y el olvido de Rebolledo. Regresan las puestas en diálogo y los vínculos porque Rebolledo "continuaba el 'decadentismo' de Tablada y el propio Nervo: liturgia erótica, edad media, joyas, faunos, tedio, desaliento y toda la imaginería de Prosas profanas" (114). Más allá de dichas similitudes, su singularidad se encuentra en "la certeza de la perfección nunca lograda" (114). Entre sus trabajos, Pacheco destaca en la antología y en el ya mencionado "Inventario" de Proceso los doce sonetos de Caro Victrix (Carne victoriosa, 1916) que marcan el influjo de Leopoldo Lugones, particularmente sus "Doce gozos" (115). Así como se señalan las influencias de Rebolledo, también se indica su maestría en tanto poeta que se desprendió del pudor que dominaba en el campo literario mexicano del momento, lo cual influyó sobre otros escritores, como López Velarde, que vieron en Rebolledo un predecesor.

A pesar de señalar el poco interés que la crítica le ha dedicado a su prosa, Pacheco subraya, a partir de la impronta de Rebolledo en "la escritura artística mexicana" (116), la relevancia de Salamandra, novela que se destaca más que los cuentos de El desencanto de Dulcinea y el relato Saga de Sigfrida la Blonda porque "significa para la literatura mexicana el testamento y despedida de la generación modernista" (1977).

24 Debido a que pronto se cumple el centenario del nacimiento de Efrén Rebolledo, José Emilio Pacheco publica el 2 de julio de 1977 un "Inventario" dedicado a la novela Salamandra, la penúltima obra de Rebolledo que, de acuerdo con su lectura centrada en ciertos motivos, personajes y situaciones, "significa para la literatura mexicana el testamento y despedida de la generación modernista" (1977). 
A Salvador Díaz Mirón, como podemos leer en una de las citas anteriores, lo vincula con Rebolledo por ser un antecedente en la audacia que, luego, caracterizará la poética de este último. Una mención especial hace de Lascas, "una de las obras centrales del modernismo en castellano" (1998) que, junto con el resto de sus textos conocidos, bastan para ubicarlo, como se plasma en la presentación que antecede sus poemas en la antología, "en la primera línea del modernismo mexicano" (1970: 33). Frente al silencio del centenario de este libro, José Emilio Pacheco escribe un artículo en Letras Libres, "Díaz Mirón en el centenario de Lascas", en septiembre de 2001, donde destaca el impacto que tuvo la publicación de este poemario que, en 1901, alcanzó quince mil ejemplares, "cifra que entre nosotros sólo han alcanzado ayer Amado Nervo y hoy Jaime Sabines" (2001: 34). Dicha popularidad no es ajena a lo que ya hemos explicado acerca de la intercomunicación que, desde fines del siglo XIX, se desarrolla entre los diferentes centros de América Latina: "Todo aquello fue obra de la primera globalización, el mercado mundial, y la aceleración de la historia provocada por el ferrocarril, el cable telegráfico y el trasatlántico" (34). Díaz Mirón, resalta, fue leído en todas partes. Así, Pacheco urde la trama de una tradición donde su compatriota es leído tanto por Rubén Darío, Leopoldo Lugones, Julio Herrera y Reissig como por los españoles Juan Ramón Jiménez y Francisco Villaespesa (Pacheco 1998). Si Gutiérrez Nájera se sitúa en el primer escalón de los poetas modernistas mexicanos, Díaz Mirón es quien lo acompaña de cerca. Pacheco desanda el sendero de una crítica que desplazó a Díaz Mirón del canon modernista y, en ese recorrido, lo reubica en el sitio que le fue negado por años. Díaz Mirón es "nuestro mejor poeta romántico que empieza donde termina Manuel Acuña" (2001: 35). Las afiliaciones rompen con los límites hispanoamericanos porque "sintetiza y resuelve en un lenguaje de mayor musicalidad las lecciones de los dos poetas españoles más célebres de su tiempo: Ramón de Campoamor y Gaspar Núñez de Arce" (35). Si bien Lascas "decepcionó al público del primer Díaz Mirón" (35), no ocurrió lo mismo con sus contemporáneos, gesto que, además de expresar la predilección pachequiana por esa obra, mantiene el interés por armar una genealogía modernista, donde reaparecen los nombres predilectos de las antologías de 1970 y 1982: “En 
cambio, [Lascas] fascinó a los poetas, lo mismo a Manuel José Othón que a José Juan Tablada y Luis G. Urbina: 'Ha escrito las estrofas más perfectas que pueda presentar hasta hoy la poesía mexicana'" (35). Una y otra vez Pacheco vuelve a Lascas, libro donde se reúnen sin conflictos el simbolismo, el parnasianismo y donde poemas como "La Giganta" existen porque Díaz Mirón supo leer a Charles Baudelaire. Lascas, como afirma Pacheco en el "Inventario. Díaz Mirón en 1980", "es un libro único sin antecedentes ni continuadores directos [...] es un preludio de la expresión futura y todos los poetas mexicanos que vinieron después le deben algo" (1980a). Valorizar a Díaz Mirón significa, además de leer su obra de otro modo, repensar el modernismo mexicano desde nuevas posiciones críticas, que no se inscriban en la imitación o en el simple traspaso de lecturas europeas. La creación, el trabajo con el lenguaje y la innovación estilística derribarán los lugares comunes, los ya transitados. Hay otras posibilidades, otros modelos, otras inspiraciones a través de las cuales es posible una lectura del movimiento modernista: "El hábito de observar el modernismo sólo como un desprendimiento de la poesía francesa ha estorbado la consideración de otros modelos, sobre todo los italianos: Leopardi en Gutiérrez Nájera, su casi contemporáneo GabrieIle D’Annunzio en Díaz Mirón" (1980a).

\section{Conclusiones}

El propósito de este trabajo fue recuperar y analizar una de las discusiones que consideramos clave en el proyecto crítico de José Emilio Pacheco. Como vimos, el modernismo ocupa un lugar sobresaliente en los debates acerca de la configuración de la tradición literaria y cultural que lo precede. Rubén Darío y Manuel Gutiérrez Nájera son recuperados, entre otros motivos, por la posibilidad de fraguar una tradición literaria que rasgó los límites nacionales. Pacheco, mediante la red de reciprocidades que construye en sus antologías y textos ensayísticos, teje un recorrido y en él rescata y relee escritores, como Amado Nervo, Ramón López Velarde y Salvador Díaz Mirón. La intención es proponer otra lectura, fundar otra perspectiva crítica que, por ejemplo, coloque a Amado Nervo en un lugar respetado, que lea a contrapelo de la perspectiva nacionalista la obra de 
López Velarde y que presente a Lascas de Díaz Mirón como obra central del modernismo. Esta nueva manera de entender la crítica no debe soslayar los vínculos existentes entre Juan José Tablada y Enríquez González Martínez con la tradición vanguardista, en particular, con el grupo Contemporáneos. Pacheco, en tanto lector y crítico, diseña una red de interrelaciones que, además de complementarse con las otras entradas dedicadas a otros escritores antologados, cumple con el anhelo de ofrecer una antología crítica sobre las letras del modernismo mexicano.

\section{Bibliografía}

Alemany Bay, Carmen. "Elecciones y lecciones poéticas de José Emilio Pacheco (Terrazas, sor Juana, Darío, Lugones y Vallejo)", en Nueva Revista de Filología Hispánica, t. 63, núm. 1 (2015): 81-101. Disponible en: <https://nrfh.colmex. mx/index.php/nrfh/article/view/1192/1189>.

Alemany Bay, Carmen. "Acercamientos de José Emilio Pacheco al modernismo mexicano: de la teoría (ensayo) a la práctica (poema)", en Poéticas. Revista de Estudios Literarios, núm. 7 (marzo de 2017): 29-49. Disponible en: <http:// poeticas.org/index.php/poeticas/article/view/65>.

BARTHES, Roland. "De la ciencia a la literatura", en El susurro del lenguaje. Más allá de la palabra y la escritura [1967]. Trad. Carlos Fernández Medrano. Barcelona: Paidós, 1987. 13-21.

Bourdieu, Pierre. "Campo intelectual y proyecto creador", en Problemas del estructuralismo [1966]. Trad. Julieta Campos, Gustavo Esteva y Alberto de Ezcurra. México: Siglo XXI, 1971. 135-182.

Colombi, Beatriz. "José Martí, veedor de la modernidad", en José Martí. Escritos sobre América. Discursos y crónicas norteamericanas. Buenos Aires: Capital Intelectual, 2010. 9-18.

Flores, Malva. Viaje de Vuelta. Estampas de una revista. México: Fondo de Cultura Económica, 2011.

García Morales, Alfonso (ed.). Los museos de la poesía. Antologías poéticas modernas en español, 1892-1941. Sevilla: Alfar, 2007.

García Gutiérrez, Rosa y Alfonso García Morales. "Una historia de las antologías poéticas mexicanas modernas (1910-1940)", en Alfonso García Morales (ed.). Los museos de la poesía. Antologías poéticas modernas en español, 18921941. Sevilla: Alfar, 2007. 459-593.

GuILLÉn, Claudio. Entre lo uno y lo diverso. Introducción a la literatura comparada. Barcelona: Crítica, 1985.

Karam Cárdenas, Tanius. "Inventario' sobre José Emilio Pacheco. Creación y periodismo cultural", en Pasión por la palabra. Homenaje a José Emilio Pacheco. México: Universidad Autónoma Metropolitana / Universidad Nacional Autónoma de México, 2013. 293-307. 
Pacheco, José Emilio. “Ernesto Mejía Sánchez. Exposición documental de Manuel Gutiérrez Nájera, 1859-1959", en Revista de la Universidad de México, 15.5 (enero 1960): 38.

Pacheco, José Emilıo. Antología del modernismo 1884-1921. México: Universidad Nacional Autónoma de México, 1970.

PACHeCO, José EMilio. "Efrén Rebolledo (1877-1929). Actualidades y anacronismos de Salamandra", en Proceso, núm. 35 (julio de 1977). Artículo en línea disponible en: <http://hemeroteca.proceso.com.mx> [consultado el 8 de mayo de 2015].

Pacheco, José Emilio. "Para volver a Rubén Darío", en Proceso, núm. 105 (noviembre de 1978). Artículo en línea disponible en: <http://hemeroteca.proceso. com.mx> [consultado el 8 de mayo de 2015].

Pacheco, José Emilio. "Díaz Mirón en 1980", en Proceso, núm. 172 (febrero de 1980a). Artículo en línea disponible en: <http://hemeroteca.proceso.com. $\mathrm{mx}>$ [consultado el 5 de mayo de 2015].

PACHeCO, José EMILIO. “Amado Nervo y Ramón López Velarde. Diálogo de los muertos", en Proceso, núm. 213 (noviembre de 1980b). Artículo en línea disponible en: <http://hemeroteca.proceso.com.mx> [consultado el 5 de mayo de 2015].

Pacheco, José Emilio. Poesía modernista. Una antología general. México: Universidad Nacional Autónoma de México, 1982a.

PACHeCO, José EmILIO. "Los periodistas. Cien años de modernismo", en Proceso, núm. 295 (junio de 1982b). Artículo en línea disponible en: <http://hemeroteca.proceso.com.mx> [consultado el 9 de mayo de 2015].

PacheCO, José Emilıo. "Palabra y violencia [José Juan Tablada]", en Proceso, núm. 308 (septiembre de 1982c). Artículo en línea disponible en: <http://hemeroteca. proceso.com.mx> [consultado el 9 de mayo de 2015].

Pacheco, José Emilıo. "Jules Laforgue (1860-1887)", en Proceso, núm. 566 (septiembre de 1987). Artículo en línea disponible en: <http://hemeroteca.proceso.com.mx> [consultado el 8 de octubre de 2015].

Pacheco, José Emilio. "Sobre López Velarde", en Revista de la Universidad de México, 43. 451 (agosto 1988): 3.

Pacheco, José Emilıo. "Urna de Díaz Mirón", en Proceso, núm. 1114 (marzo de 1998). Artículo en línea disponible en: <http://hemeroteca.proceso.com.mx> [consultado el 9 de octubre de 2015].

PaCheCO, José Emilıo. "Manuel Gutiérrez Nájera: el sueño de una noche porfiriana", en Letras Libres (febrero 2000): 20-23.

Pacheco, José Emilıo. "Díaz Mirón en el centenario de Lascas", en Letras Libres (septiembre 2001): 34-36.

Pacheco, José Emilıo. "Al centro de su otra orilla", en Rafael Gutiérrez Girardot. Modernismo. Supuestos históricos y culturales [1983]. Bogotá: Fondo de Cultura Económica, 2004.

Pacheco, José Emilio. "Rubén Darío entre dos siglos". Prólogo a Obras completas. I. Poesía de Rubén Darío. Edición de Julio Ortega con la colaboración de Nicanor Vélez. Barcelona: Galaxia Gutenberg / Círculo de lectores, 2007. 27-47. 
Pineda Franco, Adela. "El afrancesamiento modernista de la Revista Azul (18941896): ¿Un arte decadente o una apología del progreso positivista?", en Javier Pérez Siller (dir.). México Francia: Memoria de una sensibilidad común. Siglos $X I X-X X$. Tomo I. México: Centro de estudios mexicanos y centroamericanos / El Colegio de San Luis / Benemérita Universidad Autónoma de Puebla, 1998: 395-417. Disponible en línea: <http://books.openedition.org/cemca/4082>.

QuiÑóneZ, ISABEL. "Los setenta", en Manuel Fernández Perera (coord.) La literatura mexicana del siglo xx. México: Fondo de Cultura Económica / Consejo Nacional para la Cultura y las Artes / Universidad Veracruzana, 2008. 355-399.

RAMA, ÁNGEL. Rubén Darío y el modernismo (circunstancia socioeconómica de un arte americano). Venezuela: Universidad Central de Venezuela, 1970.

RAMA, ÁNGEL. "La modernización literaria latinoamericana (1870-1910)", en Hispamérica, núm. 36 (1983): 3-19.

RAMA, ÁNGEL. "Algunas sugerencias de trabajo para una aventura intelectual de integración", en AAVV. La literatura latinoamericana como proceso. Buenos Aires: Centro Editor de América Latina, 1985a. 85-97.

RAMA, ÁNGEL. Las máscaras democráticas del modernismo. Montevideo: Fundación Ángel Rama / Arca Editorial, 1985b.

Ramos, Julıo. Desencuentros de la modernidad en América Latina. Literatura y política en el siglo xIx [1989]. México: Fondo de Cultura Económica, 2003.

Ruiz Abreu, Álvaro. "Pacheco, de la crónica a la poesía", en Pasión por la palabra. Homenaje a José Emilio Pacheco. México: Universidad Autónoma Metropolitana / Universidad Nacional Autónoma de México, 2013. 251-262.

SAID, EDWARD. Beginnings: Intention and Method [1975]. New York: Johns Hopkins University Press, 1978.

Serna Arnálz, Mercedes. "José Martí, Pablo Neruda y la República en España", en Monteagvo, núm. 9 (2004): 13-24.

Stanton, Anthony. "Tres antologías: la formulación del canon", en Inventores de la tradición. Ensayos sobre poesía mexicana moderna. México: El Colegio de México / Fondo de Cultura Económica, 1998. 21-60.

SuÁREZ DE LEÓN, CARMEN. "Mis hijos de Victor Hugo, en la traducción de José Martí (1875)". Alicante: Biblioteca Virtual Miguel de Cervantes, 2012. Artículo en línea disponible en: <http://www.cervantesvirtual.com> [consultado el 15 de agosto de 2015].

Valdés, ZoÉ. "José Martí en París" (2008). Artículo en línea disponible en: <http:// www.penultimosdias.com> [consultado el 2 de mayo de 2015].

ZANETTI, SUSANA. "Modernidad y religación: una perspectiva continental (18801916)", en América Latina: Palabra, Literatura e Cultura, volume 2: Emancipaçao do Discurso. São Paulo: Unicamp, 1994. 491-534.

ZANETtI, SuSANA. "El modernismo y el intelectual como artista: Rubén Darío", en Carlos Altamirano (dir.) Historia de los intelectuales en América Latina. Buenos Aires: Katz Editores, 2008. 523-543.

Zanetti, Susana. "Traducciones, versiones y homenajes en la poesía de José Emilio Pacheco", en Orbis Tertius, vol. XV, núm. 16 (2010). Disponible en: <http:// www.orbistertius.unlp.edu.ar/numeros/numero-16/articulos/01-zanetti>. 
Rosario Pascual Battista

Doctora en Letras por la Universidad Nacional de La Plata. Docente auxiliar en "Introducción a la Literatura", "Práctica II" y "Práctica III" en la Facultad de Ciencias Humanas de la Universidad Nacional de La Pampa. Becaria posdoctoral de CONICET. Es Co-autora de Tropos, tópicos y cartografía: Figuras del espacio en la literatura latinoamericana (Universidad Nacional de La Plata. Facultad de Humanidades y Ciencias de la Educación, 2017). Ha colaborado en distintas publicaciones académicas. Sus trabajos de investigación se han centrado en la obra poética y ensayística del escritor mexicano José Emilio Pacheco. Participa en el equipo editorial de la revista Anclajes (ISSN 0329-3807, versión impresa; ISSN 1851-4669, versión en línea). 